\title{
Optimization research of radio monitoring network for the Beijing 2022 Olympic Winter Games
}

\author{
Meiying Wei, Xiaofei Zhang, Xu Yang, Xiaoying Ma* \\ \{weimeiying, zhangxf, yangxu, maxiaoying\}@srrc.org.cn \\ The State Radio Monitoring Center, Beijing, P.R.China, 100037
}

\begin{abstract}
The 24th Olympic Winter Games will be held at Beijing and Zhangjiakou in 2022. The radio security is one of the most essential work to make the Olympic Games and ceremonies go smoothly. The planning of the radio monitoring network is the basis of the radio security. This article introduced a coverage capability assess method for the radio monitoring network. A optimization scheme was brought out considering the assessment results, the local geography and construction, using the Yanqing division as an example. With this scheme, the coverage capability of the monitoring network in Yanqing division will be optimised elaborately.
\end{abstract}

Keywords: radio security, radio monitoring, Olympic Winter Games, network optimise

\section{Introduction}

The Beijing 2022 Olympic Winter Games are planning to use 26 venues, including 13 competition venues and 13 non-competition venues. These venues are distributed in three regions: Beijing, Yanqing and Zhangjiakou[1]. As shown in figure 1, the venues are very dispersed and most terrians are mountainous and complex. This situation will bring great challenges to radio security work for the Beijing 2022 Olympic Winter Games. 


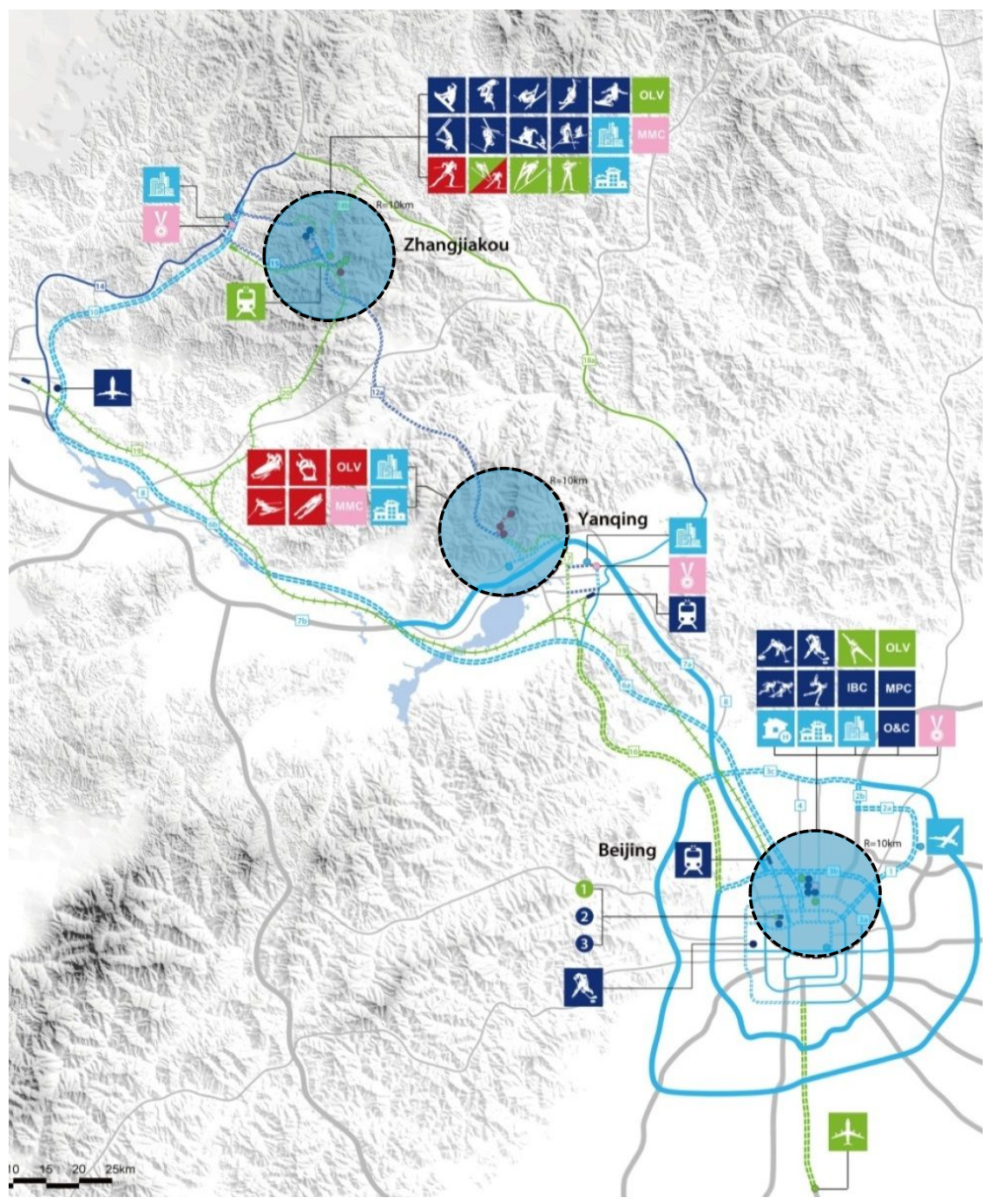

Fig. 1. Distribution of the Beijing 2022 Olympic Winter Game venues .

In recent years, the radio monitoring networks in Beijing and Hebei province are developed rapidly. Their design concepts and construction scale are both in the leading level in our country. But in Yanqing and Zhangjiakou area, the coverage of radio monitoring stations is too small to satisfy the requirements for radio security for the Olympic Games. Thus, how to optimise the radio monitoring network is the most important work for the responsible departments.

Firstly, this arcticle introduced a method to do the radio monitoring capacity evaluation with the ITU-R P.1546 model and typical radio stations used in the Olympic Games. Secondly, it avaluated the coverage capability of the existing radio monitoring stations for Yanqing competition division. Finally, it brought a scheme to optimise the monitor network in Yanqing using multi-type monitoring stations including fixed stations and protabel $/ \mathrm{mobile}$ 
stations to improve the monitoring capability, connecting with the regional geographical environment and construction condition. Through the study of this paper, the author hopes to provide theoretical basis and data support for the site selection and layout adjustment of radio monitoring network for Beijing 2022 Olympic Winter Games.

\section{The coverage capability assess method for the radio monitoring network}

The coverage capability avaluation of the radio monitoring network needs to define the following factors: the suitable propagation model for the radio waves, the transmitting paramenters of radio stations and the reiceiving parameters of the monitoring systems.

The main transmitting paramenters including frequency, power, signal bandwith and antenna height. These parameters mainly decided by the service the stations designed for. As to do the evaluation work suitable to the Beijing 2022 Olympic Winter Games, typical service radio stations should be selected according to the requirments of the Games. The reiceiving parameters of monitoring systems mainly include the location of the monitoring system, the height of the receiving attenna, the system receiving sensitivity .

\subsection{The radio propagation model in ITU-R P.1546-4 Proposal}

In 2001, the international telecommunication union (ITU) put forward the ITU-R p.1546 recommendation, named "the method of face to face prediction of ground service points in the frequency range of $30 \mathrm{MHz}$ to $3000 \mathrm{MHz}$. In this proposal, the prediction method for UHF /VHF band field intensity are given on the basis of the measured data at three transmitting frequency: $100 \mathrm{MHz}, 600 \mathrm{MHz}$ and $2000 \mathrm{MHz}$. Several probability curves of wave propagation are given when the effective transmission power is 1 kiloWatts in different propagation paths, different transmitting/ receiving antenna heights and different time and places. The method and correction formula for predicting the field intensity under different transmission frequency and power are given.

This method is suitable for broadcasting, mobile and some fixed services in the UHF/VHF band at the distance between $1 \sim 1000 \mathrm{~km}$. The proposal is also the most commonly used model for electromagnetic compatibility analysis and international frequency coordinations[2]. This paper used this propagation model to simulate and evaluate the regional coverage capability of the radio monitoring station.

\subsection{Selections of typical radio stations}

This paper selected six kinds of typical radio sevice stations used in the Olympic Games for evaluation: FM broadcasting, radio interphone relay $(150 \mathrm{MHz})$, digital trunked base station $(350 \mathrm{MHz})$, dedicated interphone $(400 \mathrm{MHz})$, digital TV broadcasting and digital trunked base station $(800 \mathrm{MHz})[3]$. The transmitting parameters which are get from practical applications can be seen in the following table: 
Table 1. Transmitting parameters for typical radio service staions

\begin{tabular}{cccccc}
\hline Parameters & $\begin{array}{c}\text { Frequence } \\
\mathrm{s}\end{array}$ & Power & Antenna Gain & Bandwith & $\begin{array}{c}\text { Antenna } \\
\text { height }\end{array}$ \\
\hline Service stations & $100 \mathrm{MHz}$ & $10 \mathrm{~kW}$ & $10 \mathrm{dBi}$ & $200 \mathrm{kHz}$ & $70 \mathrm{~m}$ \\
FM broadcasting station & $150 \mathrm{MHz}$ & $25 \mathrm{~W}$ & $5 \mathrm{dBi}$ & $12.5 \mathrm{kHz}$ & $50 \mathrm{~m}$ \\
Radio interphone relay & $350 \mathrm{MHz}$ & $25 \mathrm{~W}$ & $5 \mathrm{dBi}$ & $12.5 \mathrm{kHz}$ & $50 \mathrm{~m}$ \\
Digital trunked base station & $410 \mathrm{MHz}$ & $3 \mathrm{~W}$ & $0 \mathrm{dBi}$ & $12.5 \mathrm{kHz}$ & $1.5 \mathrm{~m}$ \\
Dedicated interphone & $700 \mathrm{MHz}$ & $1 \mathrm{~kW}$ & $10 \mathrm{dBi}$ & $8 \mathrm{MHz}$ & $70 \mathrm{~m}$ \\
Digital TV broadcasting station & $860 \mathrm{MHz}$ & $25 \mathrm{~W}$ & $5 \mathrm{dBi}$ & $12.5 \mathrm{kHz}$ & $50 \mathrm{~m}$ \\
Digital trunked base station & & & &
\end{tabular}

\subsection{Parameters of monitoring receivers}

The location and height of the receiving attennas can be get from the existing monitoring network. The antenna heigt is set to be $10 \mathrm{~m}$ according to experience. The system receiving sensitivity can be cauculated as following:

$$
\mathrm{RS}=-174+\mathrm{NF}+10 \log \mathrm{B}(\mathrm{Hz})+\mathrm{S} / \mathrm{N}+\mathrm{Lf}-\mathrm{Ga} .
$$

Where:

$\mathrm{RS}$ is the system receiving sensitivity $(\mathrm{dBm})$.

$\mathrm{NF}$ is the noise factor of the receiver.

$\mathrm{B}$ is the processing bandwith of the receiver $(\mathrm{Hz})$.

$\mathrm{S} / \mathrm{N}$ is the ratio of signal power to noise power.

$\mathrm{Lf}$ is the feeder loss of the receiving system $(\mathrm{dB})$.

$\mathrm{Ga}$ is the attenna gain of the receiving $\operatorname{system}(\mathrm{dB})$.

According to empirical values and the existing monitoring net, these parameters are set as following: $\mathrm{NF}=12 \mathrm{~dB}, \mathrm{~B}=10 \mathrm{kHz}, \mathrm{S} / \mathrm{N}=10, \mathrm{Lf}=5 \mathrm{~dB}, \mathrm{Ga}=0 \mathrm{~dB}$, so we cat get that $\mathrm{RS}=-107$ $\mathrm{dBm}$.

\section{The Coverage capability avaluation of the monitoring stations}

The coverage capability of the monitoring stations in Yanqing division is avaluated in this part as an example. Nearby the Yanqing division, there are three radio monitoring stations: Yanqing station, Changping station and Mangshan station. Their system parameters and the assess method mentioned in part 2 are used in the assessment. The evaluate results can be seen in the following figures: 


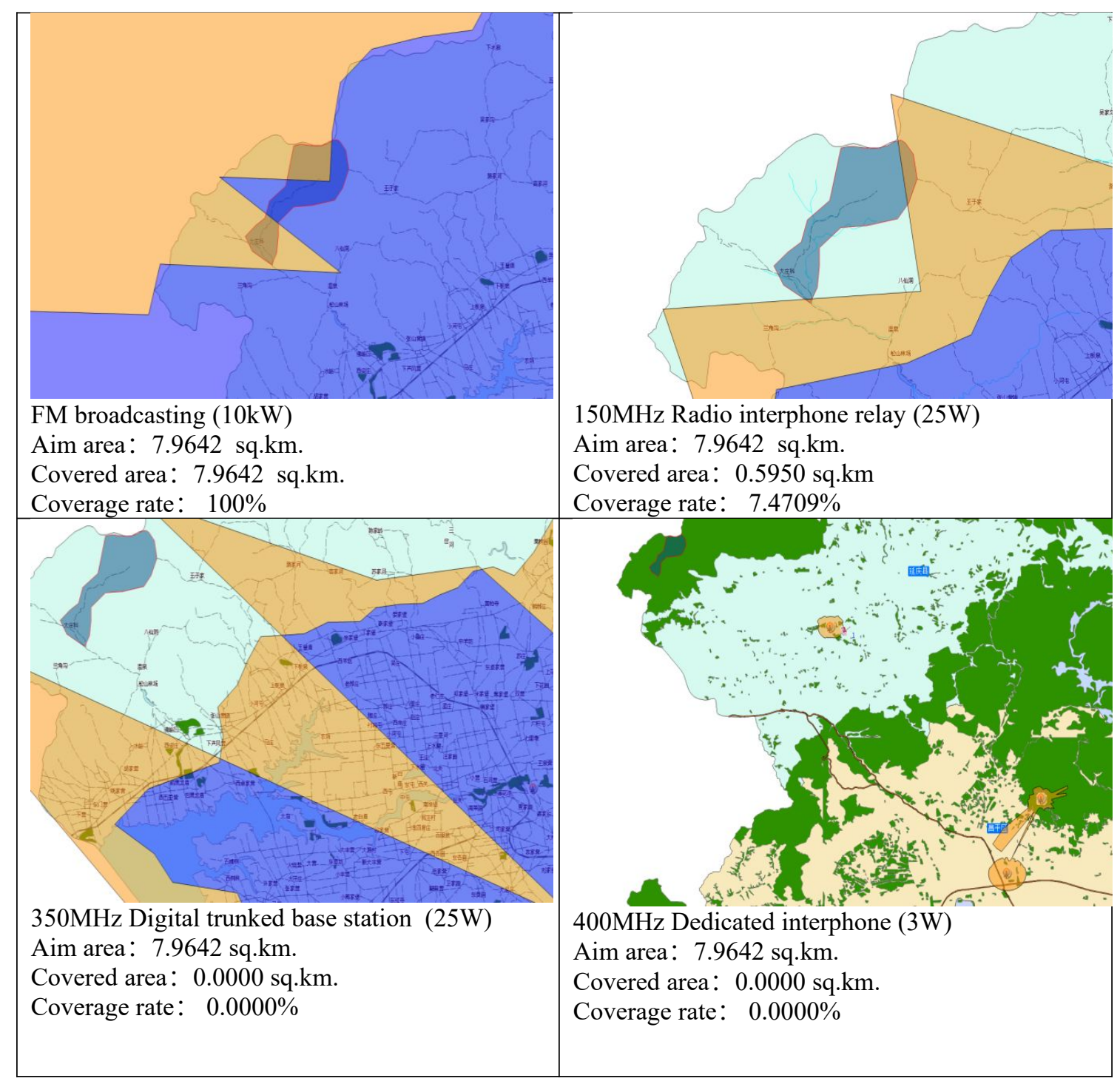




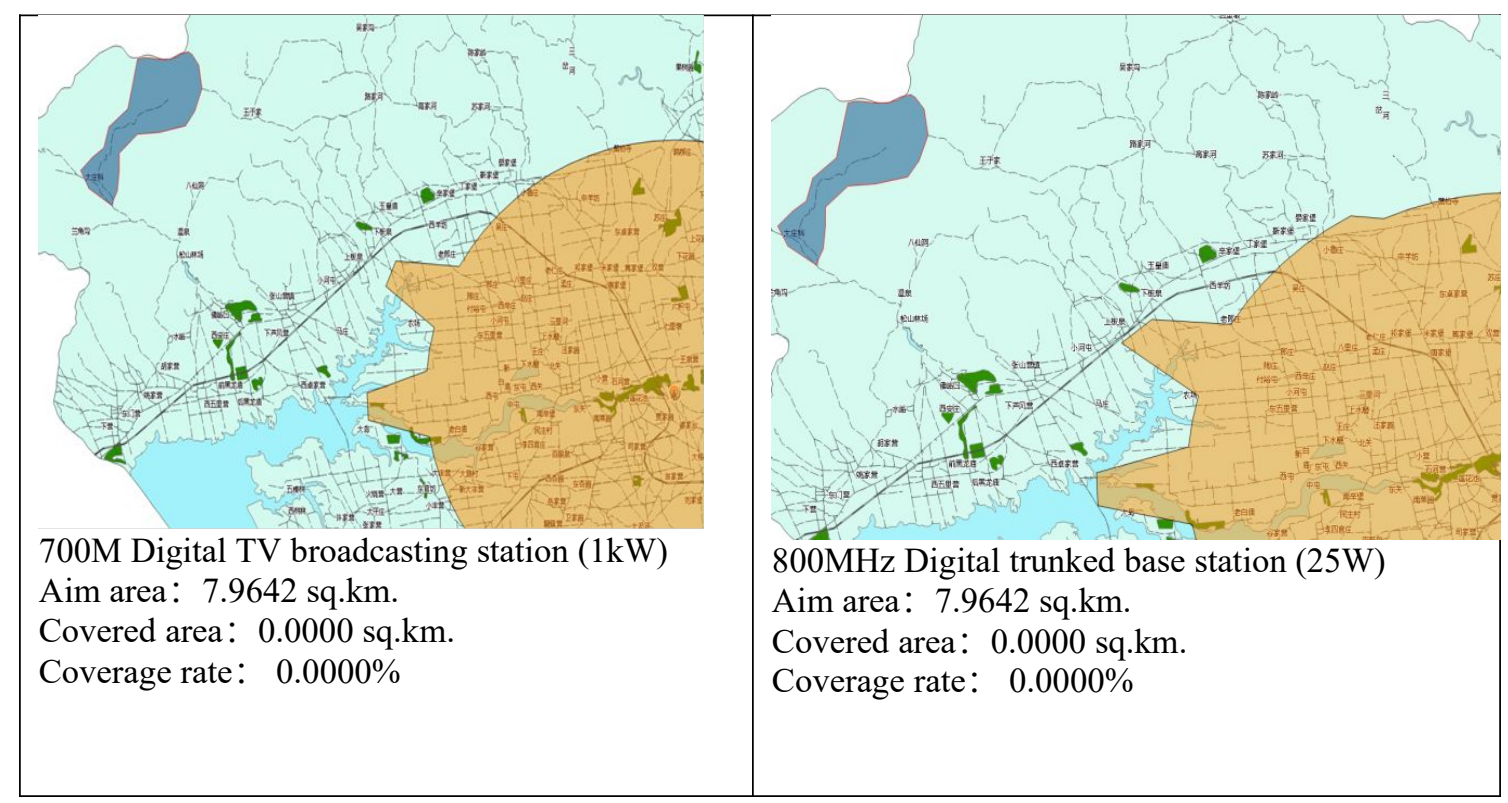

Fig. 2.Simulation results for the existing monitoring stations in Yanqing division.

The statistical simulation results for coverage rate are shown in table 2.

Table 2. Coverage rate for the monitoring staions.

\begin{tabular}{|c|c|c|c|c|c|}
\hline $\begin{array}{ll} & \text { Parameters } \\
\text { Service stations } & \\
\end{array}$ & $\begin{array}{c}\text { Frequence } \\
\mathrm{s}\end{array}$ & $\begin{array}{l}\text { Yanqing } \\
\text { Station }\end{array}$ & $\begin{array}{c}\text { Changping } \\
\text { Station }\end{array}$ & $\begin{array}{c}\text { Mangshan } \\
\text { Station }\end{array}$ & $\begin{array}{c}\text { Tatol coverage } \\
\text { rate }\end{array}$ \\
\hline FM broadcasting station & $100 \mathrm{MHz}$ & $49.2433 \%$ & $0 \%$ & $100 \%$ & $100 \%$ \\
\hline Radio interphone relay & $150 \mathrm{MHz}$ & $0 \%$ & $0 \%$ & $7.4709 \%$ & $7.4709 \%$ \\
\hline Digital trunked base station & $350 \mathrm{MHz}$ & $0 \%$ & $0 \%$ & $0 \%$ & $0 \%$ \\
\hline Dedicated interphone & $410 \mathrm{MHz}$ & $0 \%$ & $0 \%$ & $0 \%$ & $0 \%$ \\
\hline Digital TV broadcasting station & $700 \mathrm{MHz}$ & $0 \%$ & $0 \%$ & $0 \%$ & $0 \%$ \\
\hline Digital trunked base station & $860 \mathrm{MHz}$ & $0 \%$ & $0 \%$ & $0 \%$ & $0 \%$ \\
\hline
\end{tabular}

As the results showed above, the radio monitoring network in Yanqing can only be used to monitor FM broascasting stations which have large transmit power and low frequency, and also the coverage rate is only $49.2433 \%$. Its capability for monitoring the other five kinds of radio services is basically blank. It can draw a conclusion that the monitoring capability is fall far short of what is required to do the radio security work in major regional Yanqing for the Olympic Games. 


\section{Optimization scheme for the radio monitoring network}

\subsection{Layout optimization of fixed or large radio monitoring stations}

In order to maximize the use of existing monitoring resources, this paper brought the scheme which appropriately increased the monitoring station facilities, with the complete integration of the old and new systems, to protect radio safety for the Beijing Olympic Winter Games.

First, two virtual fixed radio monitoring stations located at the top of Haituo Mountain and Yanqing Olympic village respectively were added for coverage capacity evaluation. The distribution diagram of the two new virtual fixed radio monitoring stations is shown in Figure 3.

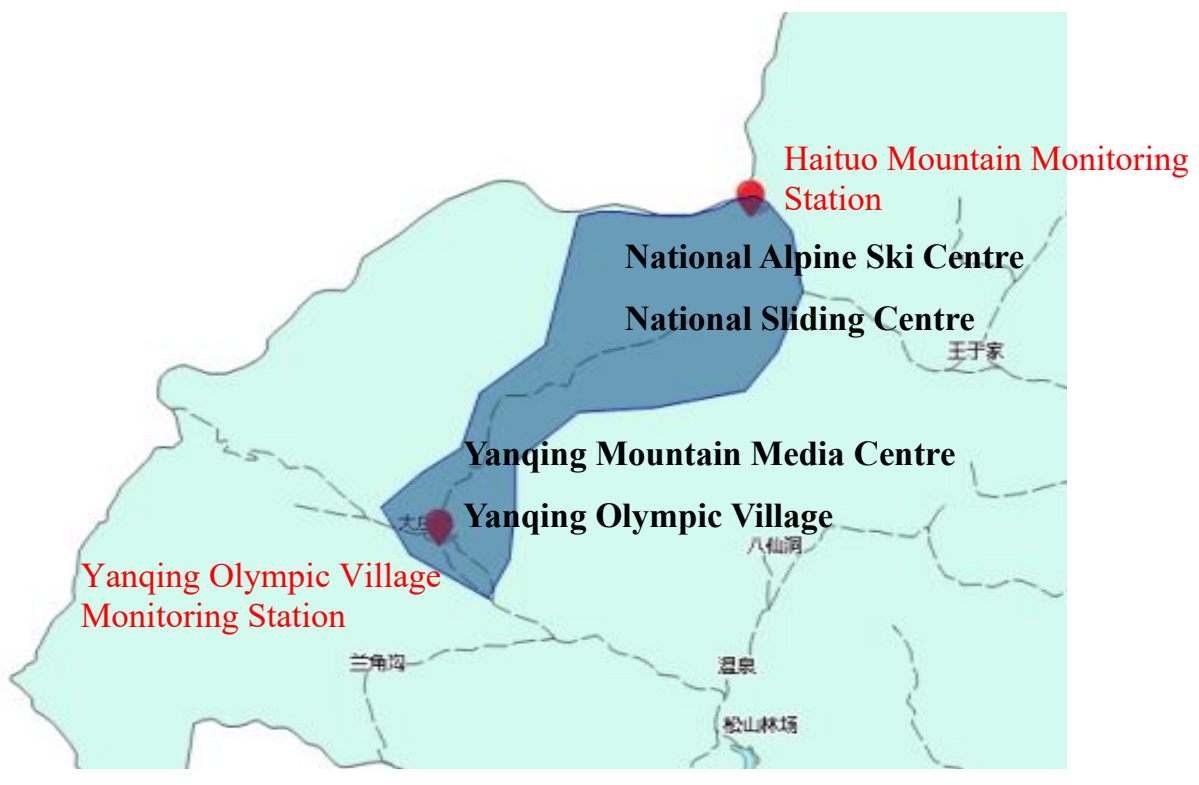

Fig. 3. Distribution map of new virtual fixed radio monitoring stations in Yanqing.

The evaluate results comparison before and after the addition of the two new virtual fixed radio monitoring stations can be seen in the following figures: 


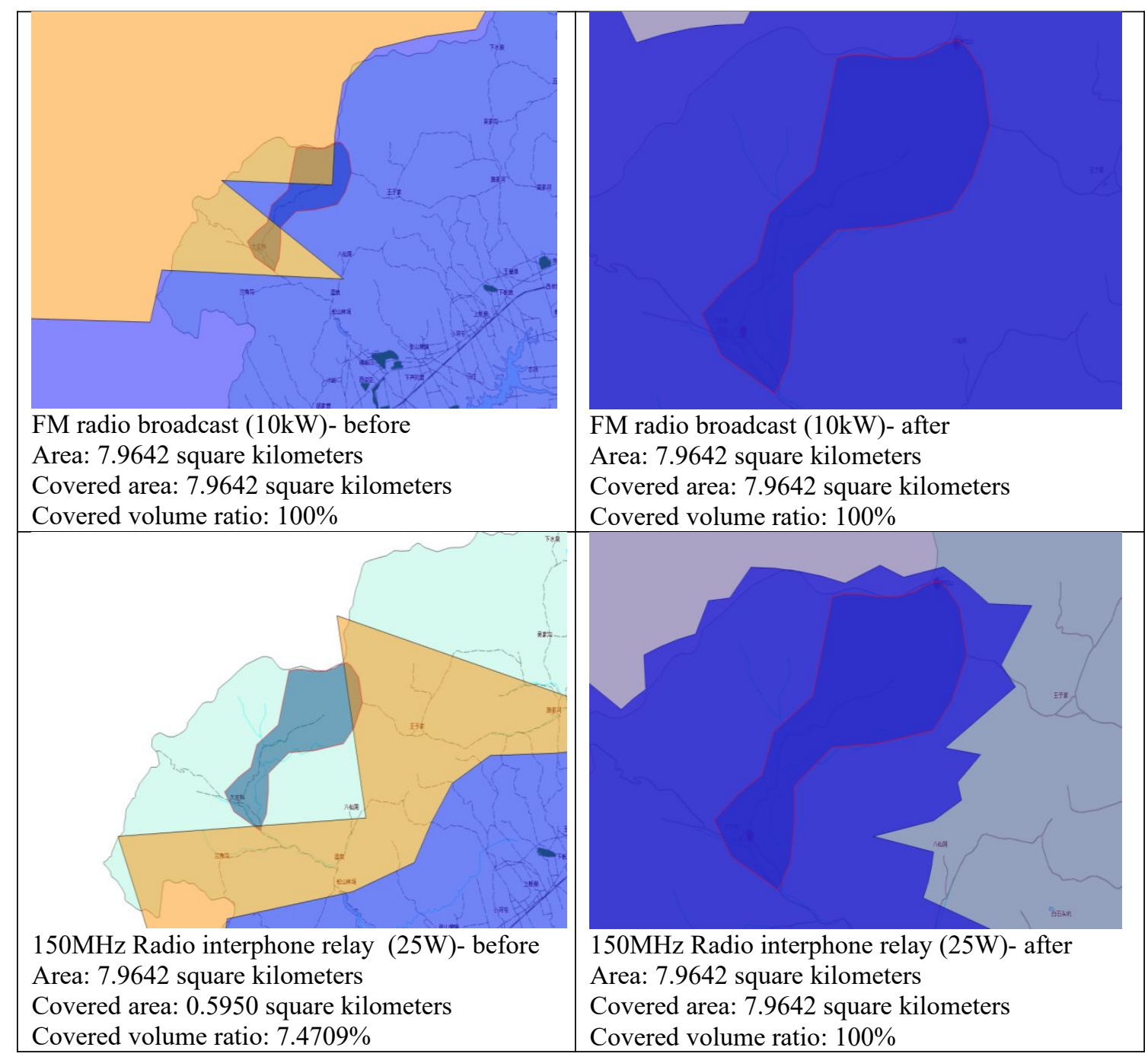




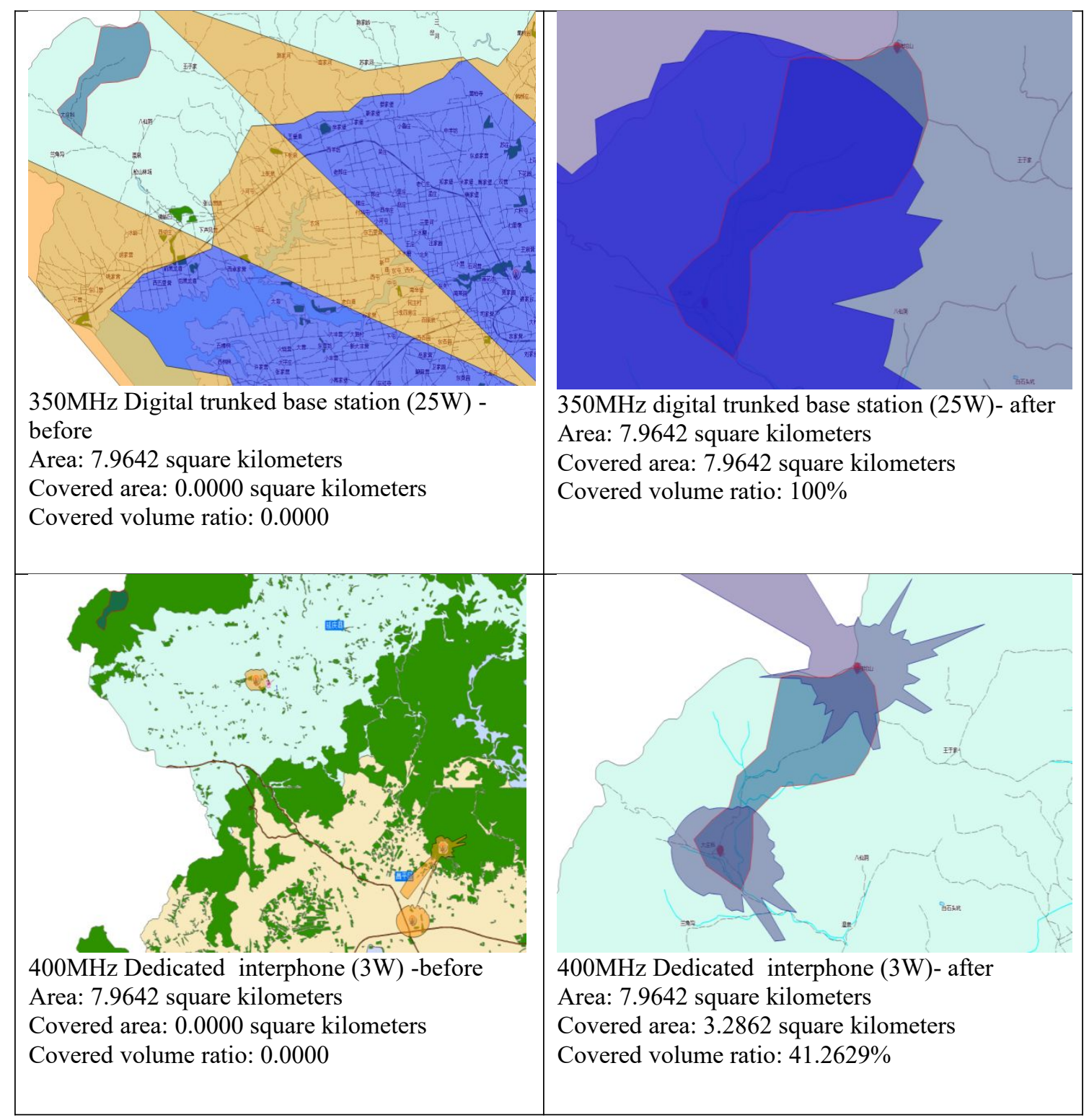




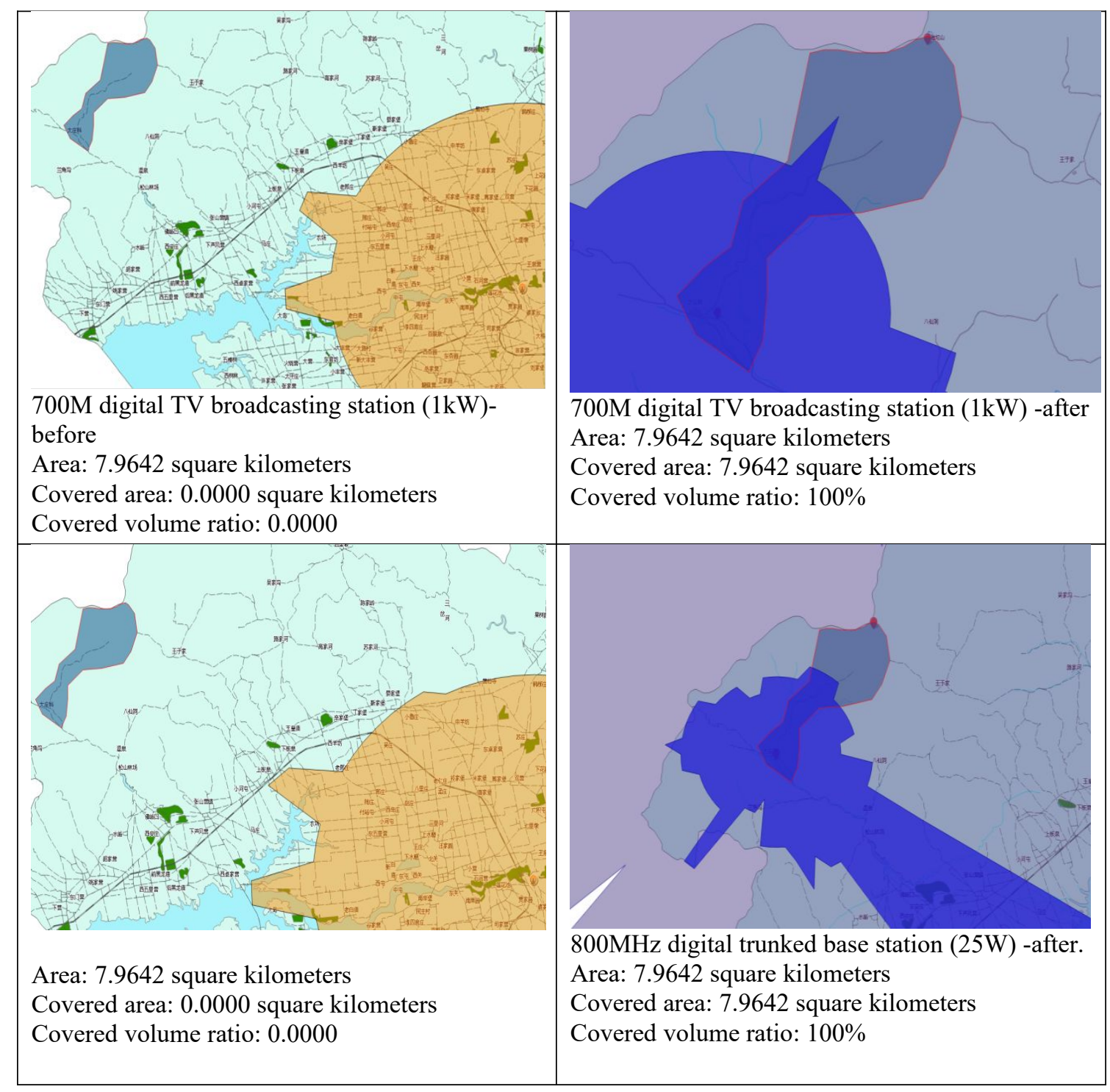

Fig. 3. Comparison of coverage simulation results before and after adding these virtual fixed monitoring stations in Yanqing.

Table 3. Coverage rate of the newly added virtual radio monitoring staions and comparison between before and after the addition .

\begin{tabular}{c|c|c|c|c|c|c}
\hline $\begin{array}{c}\text { Parameter } \\
\text { Business }\end{array}$ & Frequency & Power & $\begin{array}{c}\text { Haituo } \\
\text { Mountain } \\
\text { station }\end{array}$ & $\begin{array}{c}\text { Yanqing } \\
\text { Olympic } \\
\text { village } \\
\text { station }\end{array}$ & $\begin{array}{c}\text { Overall } \\
\text { coverage } \\
\text { before }\end{array}$ & $\begin{array}{c}\text { Overall } \\
\text { coverage } \\
\text { after }\end{array}$ \\
\hline FM broadcasting station & $100 \mathrm{MHz}$ & $10 \mathrm{~kW}$ & $100 \%$ & $100 \%$ & $100 \%$ & $100 \%$ \\
\hline
\end{tabular}




\begin{tabular}{c|c|c|c|c|c|c}
\hline Radio interphone relay & $150 \mathrm{MHz}$ & $25 \mathrm{~W}$ & $100 \%$ & $100 \%$ & $7.4709 \%$ & $100 \%$ \\
\hline $\begin{array}{c}\text { Digital trunked base } \\
\text { station }\end{array}$ & $360 \mathrm{MHz}$ & $25 \mathrm{~W}$ & $100 \%$ & $89.6437 \%$ & $0 \%$ & $100 \%$ \\
\hline $\begin{array}{c}\text { Dedicated interphone } \\
\text { Digital TV broadcasting } \\
\text { station }\end{array}$ & $410 \mathrm{MHz}$ & $3 \mathrm{~W}$ & $20.1419 \%$ & $21.1209 \%$ & $0 \%$ & $41.2629 \%$ \\
\hline $\begin{array}{c}\text { Digital trunked base } \\
\text { station }\end{array}$ & $860 \mathrm{MHz}$ & $1 \mathrm{~kW}$ & $100 \%$ & $39.3091 \%$ & $0 \%$ & $100 \%$ \\
\hline
\end{tabular}

The simulation results showing that after the addtion of the two new stations, except for the dedicated interphone, the coverage for other typical services are $100 \%$. Compared with before, the overall coverage has been greatly improved. It can be seen that the addtion of two new virtual fixed stations in the Yanqing Division can basically guarantee that the radio monitoring coverage of key protection areas is able to reach $100 \%$ for several high-power typical service stations such as FM, digital trunked communication, and digital television, but the coverage for low power stations is still poor.

\subsection{Layout optimization of portable/small radio monitoring station}

In order to increase the coverage of low power stations and realize the multi-station joint coverage for important protection areas, it is necessary to add portable/small monitoring stations near the National Alpine Ski Centre and the National Sliding Centre.

Considering the large area of the open field and the complex terrain of the mountains, it is planned to set up a station at the high point near the end of the giant slalom of the National Alpine Ski Centre for covering the Haituo mountain and both sides of the valley. The other station can be located in the National Sliding Centre to monitor the electromagnetic environment around. The distribution diagram of the two new virsual radio monitoring stations is shown in Figure 4.

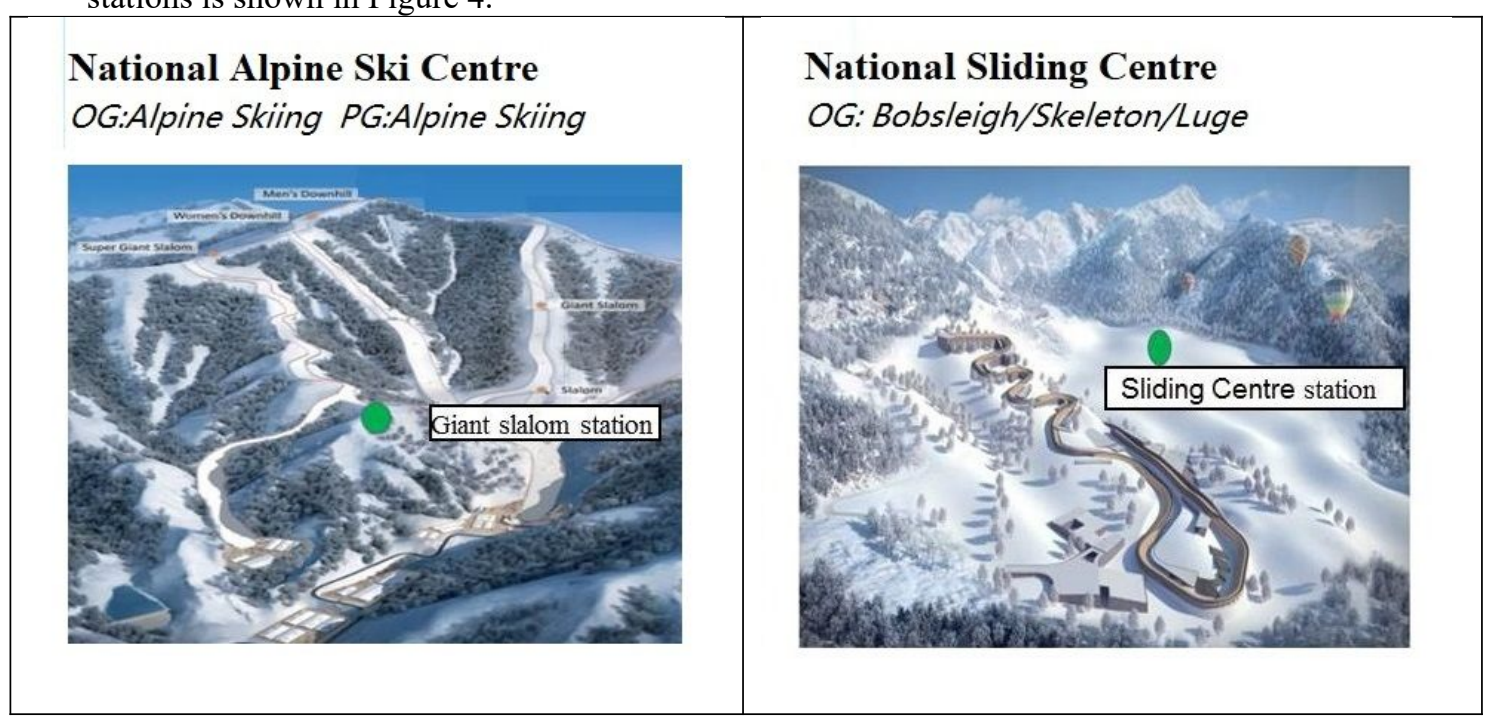


Fig. 4. Distribution map of the two new virtual radio monitoring stations in Yanqing.

After adding the two virtual portable/small stations, the monitoring coverage of $400 \mathrm{MHz}$ dedicated intercom service was recalculated, and the result is compared with the coverage only adding virtual fixed stations, as shown in Figure 5.

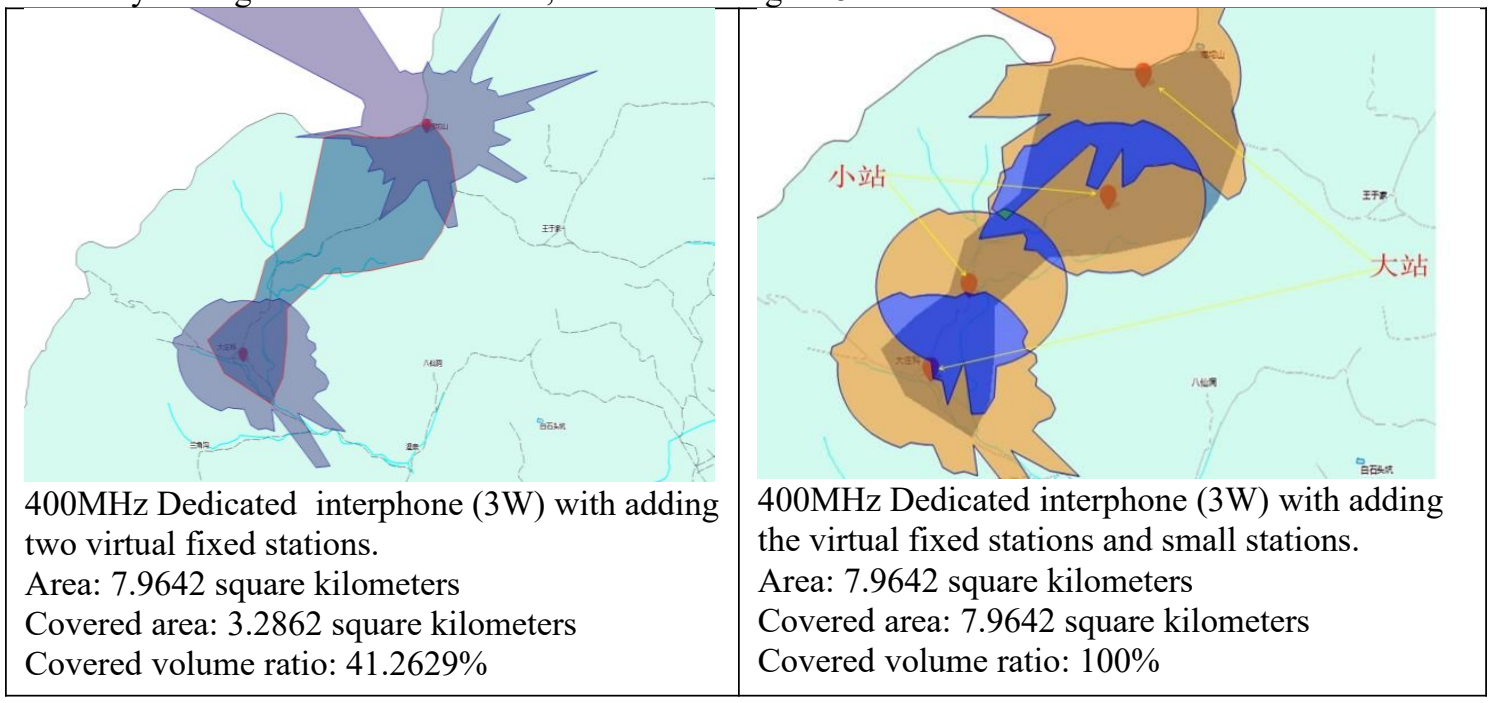

Fig. 5. Comparison of coverage simulation results after adding two virtual small monitoring stations in Yanqing.

It can be seen that through adding the 2 fixed radio monitoring stations and 2 portable/small stations, the radio monitoring network in Yanqing competition area can basically achieve $100 \%$ coverage for the typical services in theory, also for low power equipments like $400 \mathrm{MHz}$ dedicated interphones. With this layout, the coverage capability can meet the security requirements for various radio stations in the 2022 Beijing Olympic Winter Games.

\section{Conclusion}

In this paper, through calcuating the coverage of the radio monitoring network in Yanqing competition area, the layout optimization suggestions of the new adding radio monitoring stations are proposed based on the coverage evaluation results, so that the monitoring coverage effect of the competition area is greatly improved, and the monitoring coverage rate can reach to $100 \%$. The full monitoring coverage of typical service stations provides theoretical and data support for the radio management department to optimize the construction of the regional radio monitoring network, and lays a certain foundation for improving the refined technical supervision ability of the radio safety guarantee of the 2022 Olympic and Paralympic Winter Games. 


\section{Acknowledgments}

This work was supported in part by the National Key Research and Development Program of China under Grant (2018YFF0301202).

\section{References}

[1] 北京 2022 年冬奥会及冬残奥会场馆和交通规划, 2017

[2] 河北省秦皇岛地区超短波无线电监测网监测覆盖能力评估, 2013

[3] R-REP-SM.2257-2-2014-MSW-C，重大活动期间的频谱管理和监测,2014 